\title{
INFLUÊNCIA DA MICROBIOLIZAÇÃO DE SEMENTES DE FEIJÃO SOBRE A TRANSMISSÃO DE Colletotrichum lindemuthianum (Saac e Magn.) ${ }^{1}$
}

\author{
BIANCA OBES CORRÊA²; ANDRÉA BITTENCOURT MOURA3; NORIMAR D’ÁVILA DENARDIN4, VANESSA NOGUEIRA SOARES5; \\ JAQUELINE TAVARES SCHÄFER; ${ }^{6}$ JULIANE LUDWIG7.
}

\begin{abstract}
RESUMO - Isolados de Pseudomonas veronii (DFs513), Bacillus spp. (DFs093 e DFs348), Bacillus cereus (DFs769), Rodhococcus fascians (DFs843 e DFs912) e Pseudomonas fluorescens (DFs831 e DFs842), selecionados para o controle de Xanthomonas axonopdis pv. phaseoli, bem como a combinação de alguns destes isolados bacterianos, foram avaliados quanto a possível influência sobre a transmissão de Colletotrichum lindemuthianum para plântulas de feijão, a partir de sementes naturalmente infectadas e/ou infestadas. Sementes de dois lotes foram microbiolizadas com suspensões dos biocontroladores, sendo que no primeiro ensaio, em rolo de papel, realizou-se a semeadura com oito repetições de 25 sementes, incubadas a $20 \pm 2^{\circ} \mathrm{C}$. Os percentuais de germinação das sementes e incidência do patógeno foram avaliados. Em um segundo ensaio avaliou-se a transmissão do patógeno para a planta em ensaio conduzido em substrato esterilizado, incubadas por 10 dias. Realizaram-se contagens diárias das plântulas emergidas, incidência do patógeno, massa seca das folhas e raízes. Para a antibiose in vitro, um isolado de $C$. lindemuthianum foi confrontado com os isolados biocontroladores. Todos os tratamentos proporcionam aumentos de massa foliar e radicular, tanto considerando o número total quanto por planta. Os isolados, DFs831, DFs842, DFs843 e DFs912 produzem antibióticos em testes in vitro. Todos os tratamentos possibilitaram a redução da transmissão de $C$. lindemuthianum para plantas em pelo menos um dos ensaios. Porém, o isolado DFs912 (Rhodococcus fascians) destaca-se, por apresentar em todos os experimentos reduções da transmissão que variam de 40 a $67 \%$.
\end{abstract}

Termos para indexação: microbiolização de sementes, controle biológico, crestamento bacteriano comum, antracnose.

\section{INFLUENCE OF BEAN SEED MICROBIOLIZATION ON THE TRANSMISSION OF Colletotrichum lindemuthianum (Saac e Magn.)}

\begin{abstract}
Isolates of Pseudomonas veronii (DFs513), Bacillus spp. (DFs093 and DFs348), Bacillus cereus (DFs769), Rodhococcus fascians (DFs843 and DFs912) and Pseudomonas fluorescens (DFs831 and DFs842), selected for Xanthomonas axonopodis pv. phaseoli control, and a combination of some of these bacteria isolates, were evaluated for possible influence on Colletotrichum lindemuthianum transmission from naturally infected and/or infested bean seeds to seedlings. In the first trial, using the paper roll method, seeds were sown in eight replications of 25 seeds that were incubated at $20 \pm 2^{\circ} \mathrm{C}$. Germination percentage and pathogen incidence were evaluated. In the second trial, pathogen transmission to seedlings was evaluated in sterile substratum and incubated for 10 days. Daily emerged seedlings, pathogen incidence, leaf and root dry mass were
\end{abstract}

\footnotetext{
${ }^{1}$ Submetido em 01/11/2007. Aceito para publicação em 30/04/2008. Parte da Dissertação de Mestrado do primeiro autor. Projeto com suporte financeiro FAPERGS (processo 0411100). ${ }^{2}$ Bióloga, Mestre em Fitossanidade. Bolsista CAPES. Universidade Federal de Pelotas/UFPel. CP. 354. CEP: 96010-900. bianca.obescorrea@yahoo.com.br. ${ }^{3}$ Enga Agra., Dra. Prof. Departamento de Fitossanidade. Laboratório de Bacteriologia Vegetal.
}

UFPel. ${ }^{4}$ Bióloga, Dra. Prof. Laboratório de Fitobacteriologia. Departamento de Fitopatologia. Universidade de Passo Fundo/UPF. ${ }^{5}$ Graduanda Engenharia Agronômica. Bolsista PIBIC/CNPq. DFs/UFPel. ${ }^{6}$ Graduanda Engenharia Agronômica. Bolsista BIC/FAPERGS. DFs/UFPel. ${ }^{7}$ Eng $^{\text {a }}$ Agra., Doutoranda em Fitossanidade. Bolsista CNPq. DFs/UFPel. 
determined. An isolate of $C$. lindemuthianum was used against the biocontroller isolates to evaluate in vitro antibiosis. All of the treatments reduced C. lindemuthianum transmission to seedlings in at least one of the trials. However, isolate DFs912 (Rhodococcus fascians) was shown to be important and presented reductions in transmission that varied from 40 to $67 \%$ in all of the experiments. All the treatments promoted leaf and root mass increase on total number or on the number per plant. Results in vitro showed that isolates DFs831, DFs842, DFs843 and DFs912 produced antibiotic compounds.

Index terms: Seed microbiolization, biological control, common bacterial blight, anthracnose.

\section{INTRODUÇÃO}

A antracnose [Colletotrichum lindemuthianum (Sacc. e Magnus) Lams. - Scrib] é considerada uma das mais graves doenças que atingem o feijoeiro no Brasil, principalmente em localidades com baixa temperatura e alta umidade relativa do ar (Maringoni e Barros, 2002). A semente é primordial para a sobrevivência do patógeno, sendo também um dos meios mais eficientes para a introdução e disseminação deste agente a longas distâncias (Vieira, 1988). Através dela, o patógeno pode ser introduzido em áreas isentas de doença, bem como ter seu inóculo aumentado, em áreas contaminadas, pelo plantio consecutivo de sementes infestadas/infectadas (Vechiato et al., 1997; Sartori et al., 2004). Uso de sementes em boas condições sanitárias evita a disseminação do patógeno para outras áreas, a transmissão de doenças para plantas, além de contribuir para uma maior densidade populacional inicial da lavoura (Sartori et al., 2004; Vieira, 1988).

Canteri et al. (1999) indicaram a utilização de sementes sadias, livres do patógeno, a aplicação de fungicidas, rotação de culturas e a utilização de variedades resistentes para o controle da antracnose. Além destes requisitos, Cardoso (1997) e Luz (1993) incluíram a aplicação de microrganismos, como uma ferramenta com potencial para o controle de fitopatógenos, utilizada no tratamento das sementes.

Neste intuito, o presente estudo objetivou avaliar isolados biocontroladores da bactéria Xanthomonas axonopodis pv. phaseoli, isoladamente e em combinação quanto a seus possíveis efeitos sobre a transmissão para plântulas de Colletotrichum lindemuthianum presentes em sementes feijão naturalmente infestadas/infectadas, quando utilizados na microbiolização das sementes.

\section{MATERIAL E MÉTODOS}

\section{Microbiolização das sementes}

Foram utilizados dois lotes de sementes de feijão, cultivares BRS Valente (Lote A) e Líder (Lote B), com 45 e $73 \%$ de infestação/infecção inicial, respectivamente.

Os isolados bacterianos utilizados (Tabela 1) foram selecionados para biocontrole de Xanthomonas axonopodis pv. phaseoli (Zanatta, 2004) e cultivados em meio 523 de Kado e Heskett (1970) por 24 horas. Suspensões foram preparadas em solução salina ( $\mathrm{NaCl} 0,85 \%)$ e as concentrações ajustadas para $\mathrm{OD}_{540}=0,50$. Para constituição das misturas foram adicionados $20 \mathrm{~mL}$ de cada isolado (DFs093+769+831; DFs093+769+842 e DFs769+348+831) cujas concentrações também foram individualmente ajustadas para $\mathrm{OD}_{540}=0,50$, constituindo, respectivamente, as combinações M01, M02 e M03.

TABELA 1. Tratamentos utilizados na microbiolização das sementes dos dois lotes de feijão

\begin{tabular}{ccc}
\hline Tratamentos & Identificação $^{*}$ & Habitat \\
\hline DFs093 & Bacillus spp. $^{\text {DFs348 }}$ Bacillus spp. & Solo sob cultivo de feijão \\
DFs513 & Fseudomonas veronii & Túnica de cebola \\
DFs769 & Bacillus cereus & Vagem de feijão \\
DFs831 & Pseudomonas fluorescens & Solo rizosférico feijão \\
DFs842 & Pseudomonas fluorescens & Folha de feijão \\
DFs843 & Rhodococcus fascians & Folha de feijão \\
DFS912 & Rhodococcus fascians & Folha de feijão \\
${ }^{* *}$ M01:DFs093+769+831 & - & - \\
${ }^{* *}$ M02: DFs093+769+842 & - & - \\
${ }^{* *}$ M03:DFs093+348+831 & - & - \\
\hline${ }^{*}$ Determinados por sequenciamento do gene 16S rDNA(dados não publicados) & ${ }^{* *}$ Combinação dos isolados
\end{tabular}


As sementes foram agitadas, em agitador orbital a 130 rpm, a $10^{\circ} \mathrm{C}$ pelo período de cinco horas. Como testemunhas, foram utilizadas sementes imersas em solução salina $(\mathrm{NaCl}$ $0,85 \%$ ) e agitadas por cinco horas.

Quantificação de Colletotrichum lindemuthianum em lotes de sementes de feijão sobre rolo de papel

A metodologia utilizada para detecção do patógeno foi rolo de papel (Brasil, 1992). Foram utilizadas, para cada lote, 200 sementes para cada tratamento, microbiolizandoas de acordo com o item anterior. O ensaio foi montado em oito repetições de 25 sementes distribuídas entre duas folhas de papel germitest, umedecidas com água destilada. Após, os rolos foram acondicionados em sacos plásticos transparentes, incubados em germinador regulado para $20 \pm$ $2^{\circ} \mathrm{C}$ e fotoperíodo de 12 horas.

Foram consideradas sementes infestadas/infectadas as que apresentavam sintomas característicos como: lesões escuras nos coltilédones que originavam plântulas com lesões no hipocótilo, nos pecíolos e na superfície abaxial das folhas e nas nervuras. As avaliações foram realizadas após 12 dias de incubação, sendo calculada a porcentagem de germinação das sementes e incidência de $C$. lindemuthianum, em relação à testemunha.

Quantificação da transmissão de Colletotrichum lindemuthianum para plântulas

As sementes, para esta avaliação, foram microbiolizadas com suspensões dos isolados bem como suas respectivas combinações conforme a Tabela 1, sendo que para cada um dos tratamentos foram utilizadas 25 sementes, distribuídas individualmente em copos plásticos com capacidade para $50 \mathrm{~mL}$, contendo substrato comercial esterilizado. Os copos foram acondicionados em caixas plásticas, fechadas com filme plástico transparente constituindo uma câmara úmida e incubadas sob luz fluorescente contínua. Cada caixa representou uma parcela experimental. O delineamento experimental foi de blocos ao acaso com quatro repetições. Neste ensaio, foi avaliada germinação diária e total e o índice de velocidade de emergência (Nakagawa, 1999).

Após dez dias de incubação, procedeu-se à avaliação da transmissão, observando-se sintomas de lesões escuras nos cotilédones, que originavam plântulas com lesões no hipocótilo. Para avaliação da massa seca das folhas, realizouse corte destas na altura do pecíolo. O restante da planta foi retirado dos vasos, sendo o sistema radicular separado à altura do colo e lavado em água corrente. Tanto folhas, quanto raízes foram acondicionadas em sacos de papel e submetidas à secagem por $96 \mathrm{~h}$ em estufa regulada a $60^{\circ} \mathrm{C}$, para determinação da massa seca.

As sementes não germinadas foram retiradas do substrato e lavadas em água corrente e em água destilada. Posteriormente, as sementes foram avaliadas quanto à presença de $C$. lindemuthianum, submetendo-as ao teste do papel filtro (Brasil, 1995) sendo incubadas em sala climatizada por um período de sete dias a $22 \pm 2^{\circ} \mathrm{C}$, sob fotoperíodo de $12 \mathrm{~h}$. As avaliações foram efetuadas com auxílio de microscópio estereoscópico e microscópio óptico, após sete dias de incubação. Os resultados foram expressos em porcentagem em relação à testemunha.

\section{Antagonismo in vitro contra Colletotrichum lindemuthianum}

O patógeno utilizado neste ensaio foi isolado dos cotilédones das plântulas, com sintomas característicos de antracnose após as avaliações do ensaio anterior.

Os sete isolados biocontroladores DFs093, DFs513, DFs769, DFs831, DFs842, DFs843 e DFs912, foram cultivados em meio liquido de 523 Kado e Heskett (1970) por período de $72 \mathrm{~h} \mathrm{a} 28^{\circ} \mathrm{C}$. Posteriormente, foi centrifugado $1 \mathrm{~mL}$ de cada cultivo por 15 minutos em rotação correspondente à força de $10.000 \mathrm{~g}$. O sobrenadante foi retirado e submetido ao banho de ultrasom (Ultrasonic Cleaner 1440D) pelo período de 20 min. para o rompimento das células bacterianas, presentes ainda nos cultivos, obtendo-se assim, líquido contendo substâncias metabólicas e substâncias intracelulares de cada isolado bacteriano. À parte, foram vertidos $10 \mathrm{~mL}$ de meio BDA em placas de Petri. Após solidificação do meio, utilizando vasador de $5 \mathrm{~mm}$ de diâmetro, foram retirados discos do meio formando quatro orifícios eqüidistantes nos bordos das placas. Foram adicionados, aos orifícios, 20 $\mu \mathrm{L}$ do líquido formado por metabólitos de cada isolado. A seguir, depositou-se um disco de $5 \mathrm{~mm}$ de $C$. lidemuthianum no centro de cada placa. Como testemunha, um disco de micélio foi depositado em placa contendo BDA sem líquido metabólito. As placas foram incubadas à temperatura de $21 \pm$ $2{ }^{\circ} \mathrm{C}$ por 14 dias. A avaliação ocorreu quando o crescimento micelial da testemunha atingiu o bordo das placas. Neste ensaio foram realizadas quatro repetições para cada isolado bacteriano.

Observou-se presença ou não de um halo de inibição do crescimento micelial do patógeno pela ação de compostos produzidos pelos isolados biocontroladores.

\section{Análises estatísticas}

Os dados dos ensaios em rolo de papel e transmissão para plantas, foram submetidos à análise de variância e as médias comparadas pelo teste de Scott-Knott a $5 \%$ de 
probabilidade.

\section{RESULTADOS E DISCUSSÃO}

Em rolo de papel, no lote A, observou-se três níveis de controle, sendo o superior proporcionado pela combinação M03 (100\%) e o intermediário, pelos isolados DFs513, DFs842, DFs912 e a combinação M02. No entanto, somente a combinação M03 promoveu também incremento na germinação das sementes $(73 \%)$ dentre os tratamentos que reduziram a incidência de C. lindemuthianum. Por outro lado, os isolados DFs093, DFs769, DFs831 que aumentaram a germinação, não atuaram no controle do patógeno. Para o lote $\mathrm{B}$, também houve mesma estratificação em relação ao controle (Figura 1B), porém os tratamentos foram menos eficientes, provavelmente devido à condição sanitária do lote. A combinação M03 destacou-se novamente, proporcionando 91\% de controle do patógeno, seguida dos isolados DFs912 e DFs843.Não houve efeito positivo na germinação.

FIGURA 1. Germinação e incidência de Colletotrichum lindemuthianum em plantas de feijão oriundas de sementes microbiolizadas com isolados biocontroladores, sobre rolo de papel para os lotes A e B. Dados expressos em relação à testemunha $(\mathbf{1 0 0 \%})$. Letras iguais entre os tratamentos, para cada lote, não diferem estatisticamente entre si pelo teste Scott-Knot a $0,5 \%$ de probabilidade.
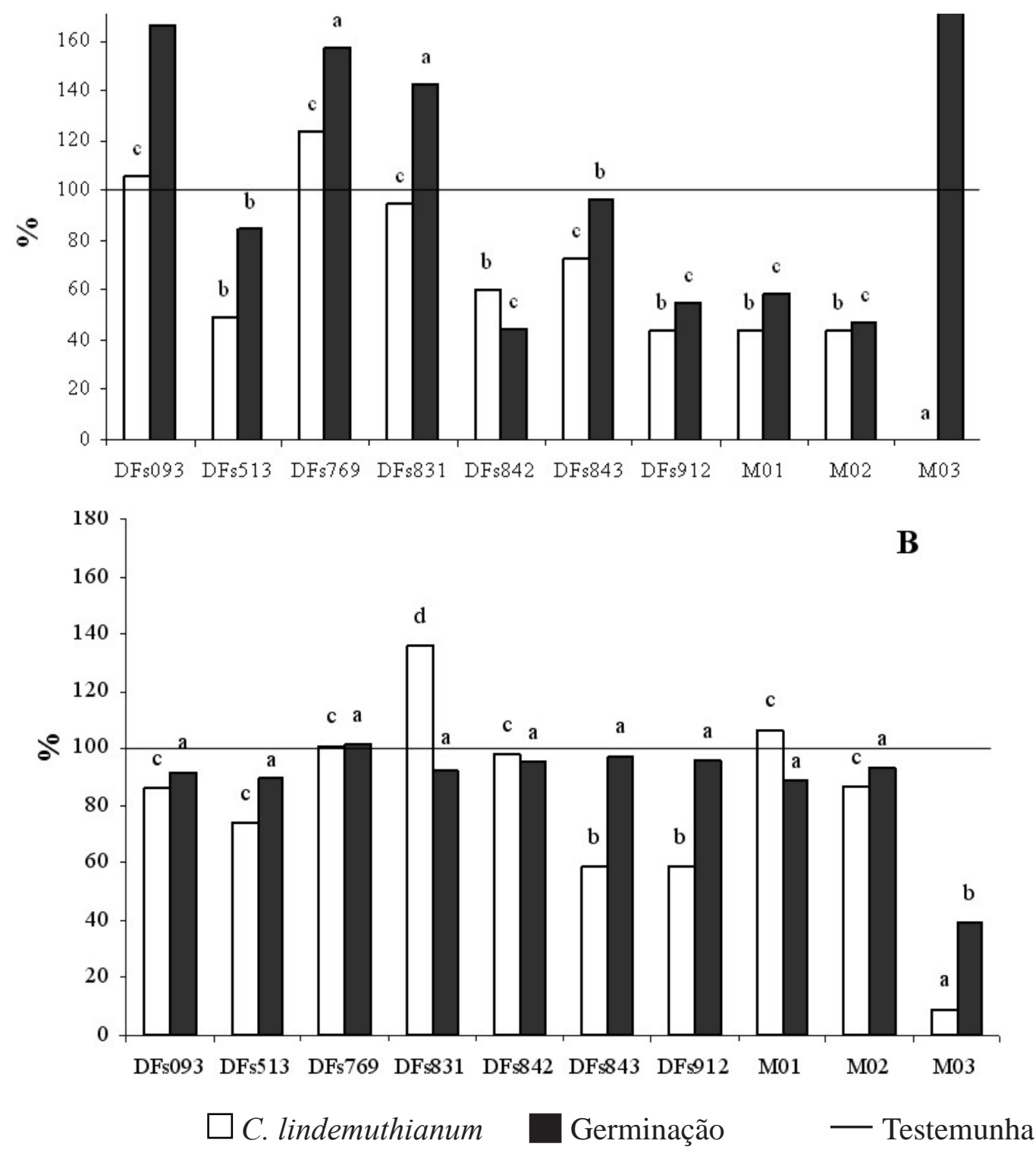
Foi possível verificar a redução da transmissão do patógeno para plântulas, proporcionada por oito dos dez tratamentos bacterianos testados. Os isolados DFs912 e DFs843, bem como a combinação M01 apresentaram comportamento estatisticamente superior, reduzindo a transmissão do patógeno em até $67 \%$ (Figura 2A). Para o lote B (Figura 2B), os tratamentos com efeito sobre o patógeno foram DFs831 e DFs912 (40\%).

FIGURA 2. Incidência de antracnose, geminação e índice de velocidade de emergência (IVE) de plântulas de feijão oriundas de sementes de feijão microbiolizadas com isolados biocontroladores para os lotes A e B. Dados expressos em relação à testemunha $(\mathbf{1 0 0 \%})$. Letras iguais entre os tratamentos, para cada lote, não diferem estatisticamente entre si pelo teste Scott-Knot a $0,5 \%$ de probabilidade.
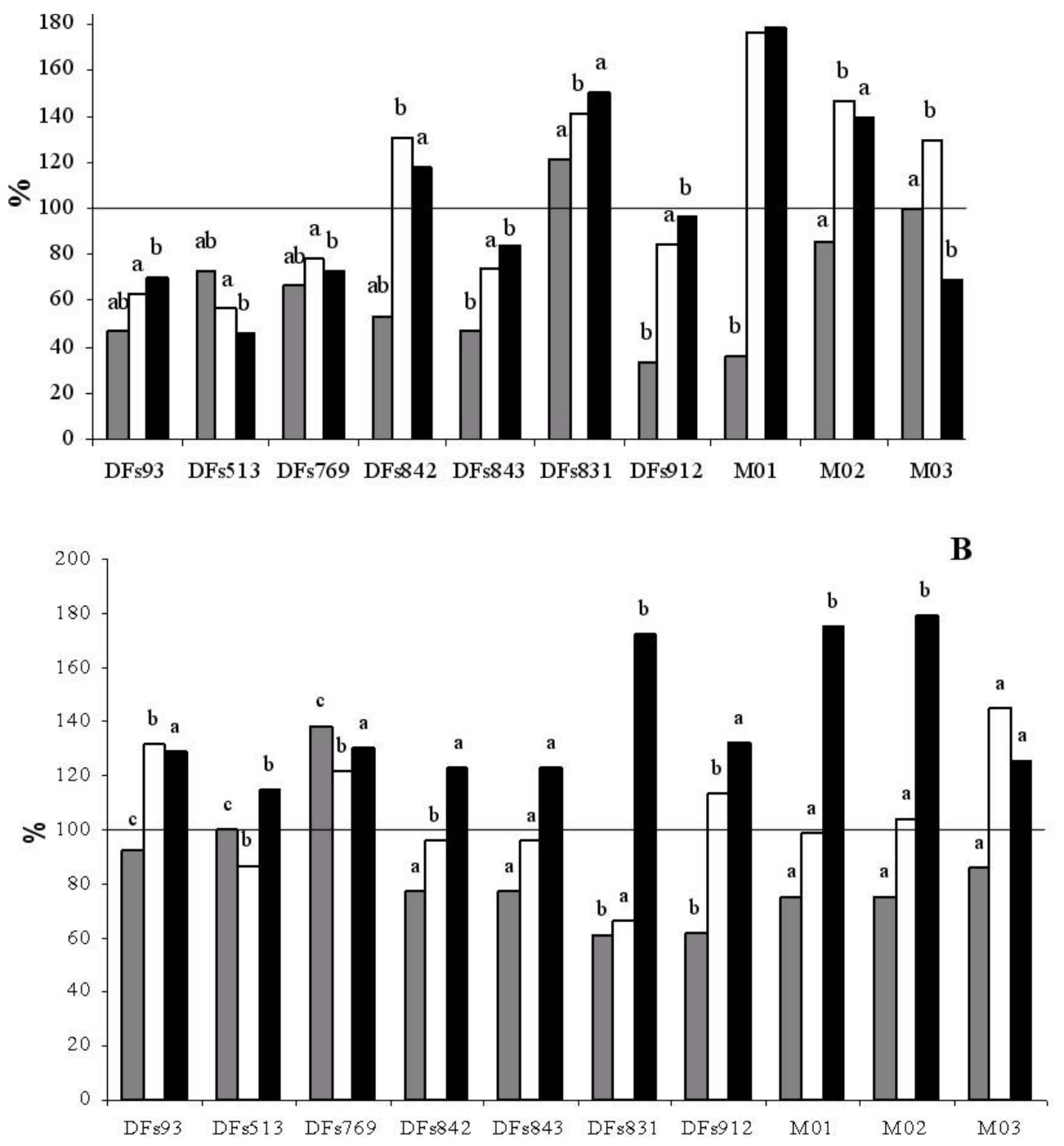

\section{C. lindemuthianum $\square$ Germinação $\square$ IVE $\quad$-Testemunha}

Alguns tratamentos permitiram aumento na porcentagem de germinação, embora maior intensidade de efeitos tenha sido observado para o IVE, principalmente no lote B. A combinação M03 se destacou para aumento de percentual de germinação e os tratamentos bacterianos DFs831, M01 e M02 para velocidade de emergência em ambos os lotes. As avaliações de massa seca, radicular e foliar, tanto no total de plantas, quanto por planta, foram superiores no lote A.

Com relação às sementes não germinadas, do ensaio em substrato esterilizado, foi observada alta incidência de fungos dos gêneros Aspergillus e Penicillium, além de crescimento bacteriano para todos os tratamentos. 
FIGURA 3. Massa seca das folhas (MSF) e massa seca das raízes (MSR) total e por número de plantas em relação à testemunha, para os lotes A e B. Dados expressos em relação à testemunha (100\%). Letras iguais entre os tratamentos, para cada lote, não diferem estatisticamente entre si pelo teste Scott-Knot a $0,5 \%$ de probabilidade.
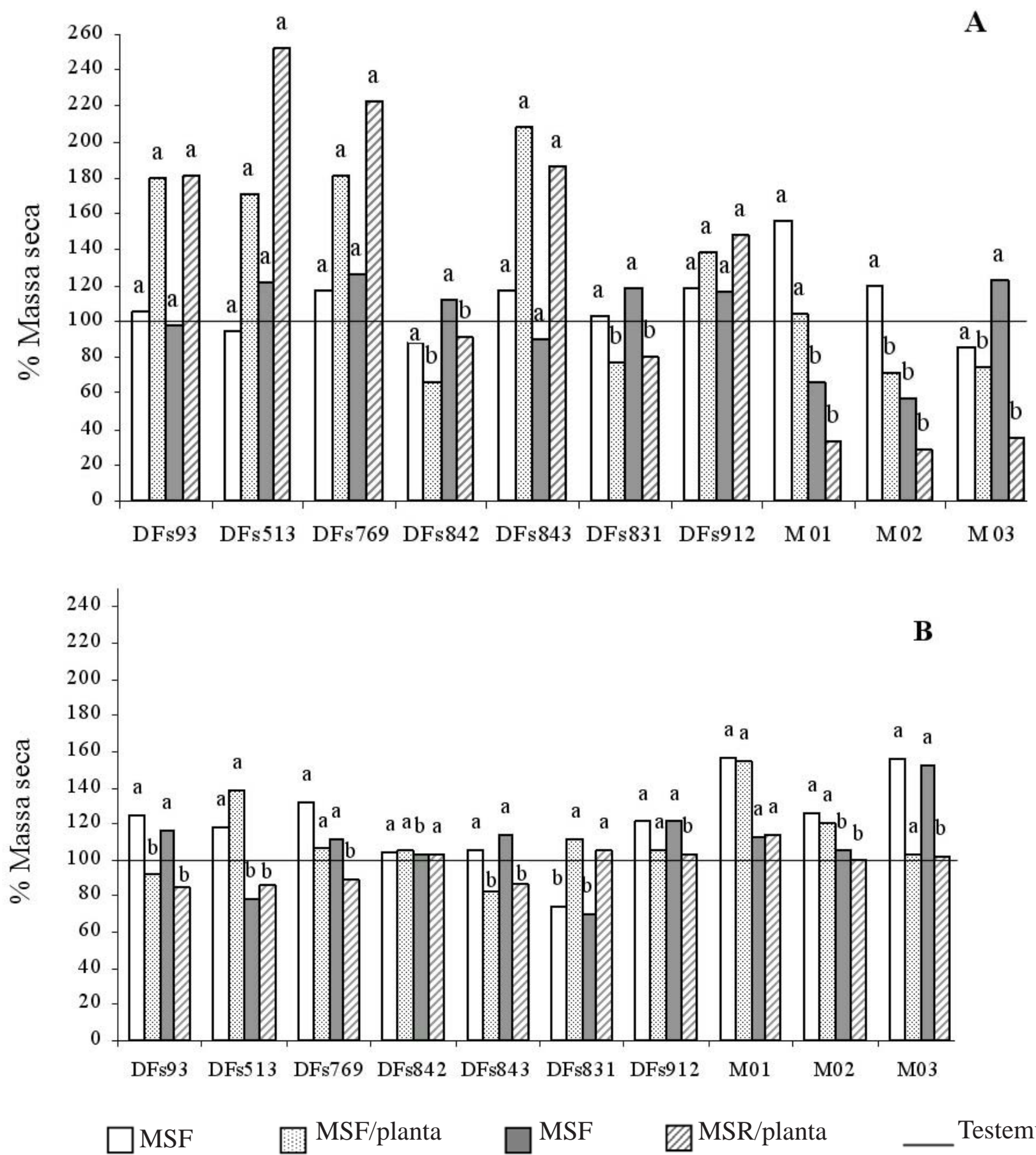

Testemunha

Nos testes in vitro, quatro isolados inibiram $C$. lindemuthianum. Os isolados com resultados positivos pertencem aos gêneros Pseudomonas (DFs831 e DFs842) e Rhodococcus (DFs843 e DFs912).
De modo geral, todos os tratamentos proporcionaram redução de transmissão do patógeno presente na semente para plântula, controlando $C$. lindemuthianum em pelo menos uma das situações avaliadas. Porém, somente o 
isolado DFs912 (Rhodococcus fascians) (variando entre 40 e $67 \%$ de controle) propiciou reduções para os dois lotes de sementes em ambos os ensaios.

A estratégia de introduzir microrganismos nas sementes infestadas/infectadas, tanto natural quanto artificialmente, visando à redução da transmissão de patógenos, é uma alternativa explorada com sucesso. Fessehaie e Walcott (2005) mostraram que microbiolizando sementes de melancia com um isolado Acidovorax avenae subsp. avenae ou de Pseudomonas fluorescens, há redução da transmissão para plântulas da bactéria patogênica Acidovorax avenae subsp. citruli previamente inoculada nas sementes. O mesmo foi estudado por Herváz et al. (1998) com Bacillus subtillis e Trichoderma harzianum, utilizados isoladamente ou em combinação para microbiolizar sementes, reduzindo a transmissão de Fusarium oxysporum f. sp. ciceris.

A combinação de agentes de biocontrole é uma opção que proporciona no controle biológico, maior estabilidade, devido ao espectro de ação dos isolados tornar-se amplo (Boer et al., 2003; Guetsky et al., 2001; Elad et al., 1994). Porém, algumas misturas não atendem a esta característica, como no caso do presente trabalho, onde as combinações utilizadas não proporcionaram estabilidade com relação aos resultados encontrados nos diferentes ensaios. Entretanto, pode-se aventar que outras combinações entre os isolados possam apresentar melhor desempenho no controle de $C$. lindemuthianum. Resultados como os encontrados neste trabalho para combinações de diferentes isolados foram observados também em plantas de grão de bico originadas de sementes microbiolizadas com a combinação Bacillus subtillis e Fusarium oxysporum (não patogênico), que resultaram em aumentos na intensidade dos sintomas quando comparados, aos tratamentos destas espécies quando utilizadas separadamente (Herváz et al., 1998).

A promoção de crescimento que os antagonistas apresentaram, em especial, acúmulo de massa foliar e radicular é comportamento conhecido em diversas espécies vegetais: pepino (Melo e Valarini, 1995), tomate (Moura e Romeiro, 2000), milho (Lucon e Melo, 2000) e feijão (Zanatta, 2004). O fato reveste-se de importância quando se pensa que estas plantas poderão explorar maior quantidade de solo, propiciando melhores condições nutricionais, e maior tolerância a condições climáticas adversas no campo (El-Abyad et al., 1993). Outra conseqüência de plantas de feijão com maior índice de velocidade de emergência, maior massa tanto radicular quanto foliar, é que estas se tornam menos sensíveis a importantes patógenos presentes no solo como Sclerotinia sclerotiorum, Fusarium oxysporum f. sp. phaseoli e Fusarium solani entre outros (Canteri et al., 1999).

Neste estudo, o isolado DFs912 se destacou na produção das plantas de feijão, em diferentes momentos, nos testes in vitro, também propiciando halos de inibição produzidos em menor número de dias e apresentando maiores diâmetros. Apesar de pertencerem a um grupo de bactérias pouco estudadas em controle biológico, pode-se aventar que este isolado atue por antibiose para o controle da doença. Esta possibilidade apóia-se no fato deste isolado apresentar atividade antifúngica contra os fungos manchadores de sementes de arroz: Alternaria, Bipolaris, Curvularia, Gerlachia e Pyricularia (Soares et al., 2006).

\section{CONCLUSÕES}

O isolado DFs912 apresenta características que possibilitam o seu uso em programa s de controle biológico de $C$. lindemuthianum. Porém, estudos posteriores fazem-se necessários, na busca dos mecanismos utilizados, bem como estudos de outras combinações entre isolados, que possibilite maior espectro de ação sobre outras doenças do feijão.

\section{AGRADECIMENTOS}

Os autores agradecem à FAPERGS disponibilizar recursos para elaboração desse trabalho.

\section{REFERÊNCIAS}

BRASIL. Ministério da Agricultura e Reforma Agrária. Regras para análises de sementes. Brasília, DF: SNDA/DNDV/CLAV, 1992. 365p.

BOER, M.; BOM, P.; KINDT, F.; KEURENTJES, J. J.B.; SLUIS, I.; VAN LOON, L. C. BAKKER, P. A. H. M. Control of Fusarium wilt of radish by combining Pseudomonas putida strains that have different disease suppression mechanisms. Phytopathology, Raleigh, v.93, n.5, p.626-632, 2003.

CANTERI, M. G.; PRIA, M. D.; SILVA, O. C. Principais doenças fúngicas para manejo econômico e ecológico. Ponta Grossa: UEPG, 1999. 178p.

CANTERI, M.G.; ALTHATUS, R.A.; VIRGENS FILHO, J.S.; GIGLIOTO, E.A.; GODOY, C.V. SASM - Agri: Sistema para análise e separação de médias em experimentos agrícolas pelos métodos Scot-knott, Tukey e Duncan. Revista Brasileira de Agrocomputação, Ponta Grossa, v.1, n.2, p.18-24, 2001. 
CARDOSO, J. E.; SILVA, S. A. G.; MARQUES, E. E. Controle químico e biológico das podridões radiculares do feijoeiro comum. Fitopatologia Brasileira, Brasília, DF, v. 22, n. 1, p. 39-44, 1997.

ELAD, Y.; KÖHL, J.; FOKKEMA, N. J. Control of infection and sporulation of Botrytis cinerea on bean and tomato by saprophytic yeasts. Phytopathology, Raleigh, v. 84, n.10, p.1193-1199, 1994.

EL-ABYAD, M; EL-SAYED, M. A.; EL-SHANSHOURY, A. R.; EL-SABBAGH, S. H. Towards the biological control of fungal and bacterial diseases of tomato using antagonistic Streptomyces spp. Plant and Soil, Dordrecht, v. 149, n. 2, p. 185-195, 1993.

FESSEHAIE, A.; WALCOTT, R. R. Biological control protect watermelon blossoms and seed from infection by Acidovorax avenae subsp. citrulli. Phytopathology, Raleigh, v. 95, n. 4, p. 413-419, 2005.

GUETSKY, R.; SHTIENBERG, D., ELAD, Y.; DINOOR A. Improving biological control by combining biocontrol agents with several mechanisms of disease suppression. Phytopathology, Raleigh, v. 92, n. 9, p. 976-985, 2001.

HERVÁS, A.; LANDA, B.; DATNOFF, L. E. R.; JIMÉNEZDÍAZ, M. Effects of commercial and indigenous microorganisms on Fusarium wilt development in chickpea. Biological Control, Orlando, v. 13, n. 3, p. 166-176, 1998.

KADO, C. I.; HESKETT, M. G. Selective media for isolation of Agrobacterium, Corynebacterium, Erwinia, Pseudomonas and Xanthomonas. Phytopathology, Raleigh, v.60, n.8 p. 2430, 1970.

LUCON, C. M. M.; MELO, I.S. Efeito da bacterização de sementes no desenvolvimento de plantas de milho e no controle de Fusarium moniliforme. Fitopatologia Brasileira, Brasília, DF, v. 25, n. 4, p. 529-537, 2000.

LUZ, W.C. Microbiolização de sementes para o controle biológico de doenças de plantas. Revisão Anual de Patologia de Plantas, Passo Fundo, v. 1, p. 33-77, 1993.

MARINGONI, A. C; BARROS, E. M. de. Ocorrência de isolados de Colletotrichum lindemuthianum resistentes a fungicidas benzimidazóis. Summa Phytopathologica, Botucatu, v. 28, n 2, p. 197-200, 2002.

MELO I. S.; VALARINI, P.J. Potencial de rizobactérias no controle de Fusarium solani (Mart.) Sacc. em pepino (Cucumis sativum L.). Scientia Agrícola, Piracicaba, v. 52, n. 2, p. 326330, 1995.

MOURA, A.B.; ROMEIRO, R. da S. Actinomicetos préselecionados para controle de Ralstonia solanacearum, como promotores de crescimento em tomateiro. Revista Ceres, Viçosa, v.47, n. 247, p.613-626, 2000.

NAKAGAWA, J. Testes de vigor baseados no desempenho de plântulas. In: KRZYZANOWSKI, C. F.; VIEIRA, R. D.; FRANÇA-NETO, J. B. Vigor de sementes: conceitos e testes. Londrina: ABRATES, 1999. p.1-24.

SOARES, V.N.; MOURA, A.B.; GONÇALVES, V.P. Prospecção por bactérias produtoras de antibióticos ativos contra fungos causadores de manchas foliares em arroz. In: CONGRESSO DE INICIAÇÃO CIENTÍFICA, 15.; ENCONTRO DE PÓS-GRADUAÇÃO, 8., 2006. Pelotas. Anais.... 2006. 1 CD-ROM.

SARTORI, A. F; REIS, E. M. e CASA, R. T. Quantificação da transmissão de Fusarium moniliforme de sementes para plântulas de milho. Fitopatologia Brasileira, Brasília, DF, v. 29, n. 4, p. 456-458, 2004.

VECHIATO, M. H.; CASTRO, J. L. de; ISHIMURA, I.; SABINO, J. C.; MENTEN, J. O.M. Antracnose do feijoeiro: correlação entre severidade em vagens e a incidência do patógeno nas sementes. Fitopatologia Brasileira, Brasília, DF, v. 22, n. 2, p.159-163, 1997.

VIEIRA, C. Doenças e pragas do feijoeiro. Viçosa: UFV, 1988. 231p.

ZANATTA, Z. G. C. N. Potencial de bactérias para biocontrole de Xanthomonas axonopodis pv. phaseoli. 2004. 67f. Tese (Doutorado em Fitossanidade) - Faculdade de Agronomia Eliseu Maciel, Universidade Federal de Pelotas, Pelotas. 